Article

\title{
Collagen/Polyethylene Oxide Nanofibrous Membranes with Improved Hemostasis and Cytocompatibility for Wound Dressing
}

\author{
Xinzhe Zhao ${ }^{\circledR}$, Jing Gao *, Xingyou Hu, Huiwen Guo, Fujun Wang, Yansha Qiao and Lu Wang * \\ Key Laboratory of Textile Science and Technology of Ministry of Education and College of Textiles, \\ Donghua University, Shanghai 201620, China; zz982351908@163.com (X.Z.); huxingyou@126.com (X.H.); \\ 18817831388@163.com (H.G.); wfj@dhu.edu.cn (F.W.); qiaoys233@163.com (Y.Q.) \\ * Correspondence: gao2001jing@dhu.edu.cn (J.G.); wanglu@dhu.edu.cn (L.W.); Tel.: +86-21-6779-2637 (L.W.)
}

Received: 28 June 2018; Accepted: 16 July 2018; Published: 26 July 2018

\begin{abstract}
As a promising agent for biomedical application, collagen has been used as a nanofiber to architecturally mimic its fibrillar structure in Extracellular Matrix (ECM); however, it has to be modified by techniques, such as crosslinking, to overcome its limitations in structural stability along with potential toxicity. Here, we prepared collagen/polyethylene oxide (PEO) nanofibrous membranes with varying crosslinking degrees and their properties, such as water stability, mechanical properties, blood clotting capacity and cytocompatibility, were studied systematically. By investigating the relationship between crosslinking degree and their properties, nanofibrous membranes with improved morphology retention, blood clotting capacity and cytocompatibility have been achieved. The result of circular dichroism measurement demonstrated that a triple helical fraction around $60.5 \%$ was retained. Moreover, the electrospun collagen/PEO at crosslinking degrees above $60.6 \%$ could maintain more than $72 \%$ of its original weight and its nanofibrous morphology under physiological conditions could be well preserved for up to 7 days. Furthermore, the crosslinked collagen/PEO membrane could provide a more friendly and suitable environment to promote cell proliferation, and about $70 \%$ of the clot can be formed in $5 \mathrm{~min}$. With its superior performance in water stability, hemostasis and cytocompatibility, we anticipate that this nanofibrous membrane has great potential for wound dressing.
\end{abstract}

Keywords: collagen; morphology retention; hemostasis; cytocompatibility; wound dressing

\section{Introduction}

As the largest organ, the skin can protect people from pathogens and excessive water loss. When it gets injured, an ideal wound dressing should serve as a barrier against dust and microorganisms, maintain a favourable moist environment for the wound healing and allow gas permeability [1]. Also, it should benefit effective promotion of cell adhesion and proliferation, control of bleeding while reducing or even stopping oozing after the hemostasis process. Many types of natural substances are promising agents to prepare a wound dressing which is capable of accelerating wound healing and promoting hemostasis, such as collagen.

Collagen, as a widely used material for biomedical applications, has gained broad clinical and consumer acceptance as a safe material [2]. As a major fibrous protein in extracellular matrix (ECM), collagen plays a predominant role in maintaining the biological and structural integrity of ECM [3]. The fibrillar structure of collagen is important for cell attachment, proliferation, and differentiation [4]. To architecturally mimic that structure, a nonwoven matrix from collagen, which is interesting for use in wound healing processes, can be easily produced via electrospinning [5-9]. In addition to the 
promotion of cell adhesion and proliferation, this collagen electrospun membrane is intended to induce platelet adhesion and aggregation to promote the coagulation process which is favorable for using as a wound dressing.

However, after electrospinning, water-insoluble collagen becomes soluble and the collagen nanofibers become swollen and lose fibrillary structure when exposed to water [10]. This is the result of the lack of the natural crosslinks which are generated in the native collagen fibrous structure by covalent and hydrogen bonds and are indispensable for the natural collagen network to gain its level of mechanical strength [11]. In order to maintain the nanofibrous structure and enhance mechanical properties of collagen, various crosslinking techniques have been used. Up to now, several physical and chemical methods have been reported for crosslinking collagen and collagen-based materials. Dehydrothermal treatment and UV irradiation are common methods of physical crosslinking [12,13]. However, compared with chemical crosslinking, they are less efficient. The physically crosslinked collagen would be nearly fully degraded after incubation for $24 \mathrm{~h} \mathrm{[14].} \mathrm{Compared} \mathrm{with} \mathrm{physical}$ crosslinking, chemical crosslinking could efficiently enhance the mechanical properties and water stability of electrospun collagen. Many chemicals such as formaldehyde, glutaraldehyde, diisocyanates, carbodiimide and genipin, have been used as chemically crosslinking agents [15-20]. Among them, 1-ethyl-3-(3-dimethylaminopropyl) carbodiimide (EDC)/ $\mathrm{N}$-hydroxysuccinimide (NHS) and genipin were considered less cytotoxic, but the crosslinked fibers showed inadequate water stability in aqueous or high humidity environments $[5,21]$. Furthermore, genipin and EDC/NHS has been reported to be cytotoxic at some concentrations depending on cell type (typically $0.5-5 \mathrm{mM}$ ) [21,22]. With dialdehyde groups, glutaraldehyde (GA) is the most widely used crosslinking agent, due to its high efficiency, low price and crosslinking of a large number of amino groups over a varying range of distances which makes it ideal for biological applications [11]. The aldehyde group of glutaraldehyde can induce Schiff-based intermediates with amino groups of lysyl and hydroxylysyl of collagen. Schiff-based intermediates are linked further to form larger crosslinked entities. So, covalent chemical crosslinking of neighboring collagen fibrils is achieved by using GA crosslinking [23]. It has been reported that the potential cytotoxicity of GA maybe due to the residues of unreacted GA and leaching out as the materials degrade. However, several previous studies have demonstrated evidence of no cytotoxic effect of GA crosslinked collagen followed by glycine quenching and washing steps [15,24].

Among the previous studies of collagen crosslinking, several have investigated the relationship between mechanical or thermal properties and the degree of crosslinking [25,26]. Moreover, there were also some studies about the difference between non-crosslinked and crosslinked collagen effects on the cytocompatibility and also different kinds of crosslinking agents [10,26-30]. However, whether there is a relationship between the degree of crosslinking and cytocompatibility remains to be confirmed. On the other hand, to our knowledge, few reports have focused on the hemostatic properties of electrospun collagen with different degrees of crosslinking. Consequently, in order to provide a basis for the crosslinking of electrospun collagen, whether there is diversity among electrospun collagen, crosslinked to varied degrees in terms of cytocompatibility and hemostasis, needs to be explored. Therefore, in this study, a small amount of polyethylene oxide (PEO) was added into solutions to facilitate electrospinning. As a water-soluble polymer with good biocompatibility and low toxicity, $\mathrm{PEO}$ is quite feasible and versatile for electrospinning. It can be added to aid electrospinning by increasing polymer chain entanglements and can be subsequently extracted from the nanofibers by incubating in water with only collagen remaining. An electrospun collagen/PEO membrane with varied degree of crosslinking was obtained by adjusting the time for crosslinking. Subsequently, how the degree of crosslinking impacts the properties of collagen electrospun nanofibers, mechanical performance, water stability, blood clotting capacity and cytocompatibility was evaluated. Finally, because its compositional and structural mimicry of the ECM and satisfactory performance in the hemostatic process, the wound dressing was predicted to be effective in promoting cell adhesion and proliferation and controlling bleeding as an ideal choice for the wound dressing. 


\section{Materials and Methods}

\subsection{Materials}

Type I freeze-dried collagen foam from bovine tendon was provided by Qi sheng Biological Agent Co., Ltd. (Shanghai, China). Polyethylene oxide (PEO, Mm = $90 \mathrm{kDa}$ ) from J \&K Scientific Ltd. (Shanghai, China) was blended with collagen to improve the spinnability of collagen. 1,1,1,3,3,3-hexafluoro-2-propanol (HFIP, Purity $\geq 99 \%$ ) from TCI Shanghai (Shanghai, China) and Acetic acid (HAc) from Shanghai Ling Feng Chemical Reagent Co., Ltd. (Shanghai, China) were used to dissolve type I collagen. A crosslinking agent of aqueous glutaraldehyde (GA) solution (25\%) was supplied by Aladdin Bio-chemical Technology Co., Ltd. (Shanghai, China) In addition, 2,4,6-Trinitrobenzenesulfonic acid (TNBS, 5\%) from Sigma (Shanghai, China) was used to test the degree of crosslinking. All chemicals were used directly without further treatment.

\subsection{Fabrication of Nanofibrous Nonwovens}

Electrospinning solution ( $4 \mathrm{wt} \%$ ) was prepared by dissolving Type I collagen from bovine tendon and Polyethylene oxide with 4:1 $(w / w)$ ratio in a binary solvent mixture of HFIP and HAc with 1:1 $(v / v)$ ratio. During electrospinning, the solution was loaded into a $5 \mathrm{~mL}$ syringe with a 20-gauge metal spinneret and then it was extruded by an infusion syringe pump (KD Scientific Inc., Holliston, MA, USA) at a feeding rate of $1.0 \mathrm{~mL} \mathrm{~h}^{-1}$. The applied voltage was set at $12 \mathrm{kV}$ and the plate collector was placed at $20 \mathrm{~cm}$ distance. Finally, the aluminium foil was placed under vacuum at room temperature for $48 \mathrm{~h}$ to remove the residual solvents. For the crosslinking, the nanofibrous membranes were placed in a desiccator containing $25 \%(v / v)$ glutaraldehyde aqueous solution for a series of time to obtain different degrees of crosslinking. Hereafter, the crosslinked samples were sequentially washed in $5 \%, 10 \%, 25 \%, 50 \%$ and $75 \%(v / v)$ phosphate buffered saline prepared in ethanol for $15 \mathrm{~min}$ followed by two Phosphate-buffered saline (PBS) rinses to reduce the swelling of nanofibers induced by solvent [25]. Afterwards, the membranes employed $0.2 \mathrm{~mol} \mathrm{~L}^{-1}$ glycine aqueous solution to block unreacted aldehyde groups. Finally, the membranes were rinsed in PBS $(\mathrm{pH}=7.4)$ for $20 \mathrm{~min}$ three times followed by freeze-drying for $24 \mathrm{~h}$.

\subsection{Circular Dichroism Measurement (CD)}

$\mathrm{CD}$ measurements were utilized to evaluate the fraction of the triple helical structure present in electrospun collagen. The untreated collagen blended with PEO with the weight ratio at 4:1, electrospun collagen membrane without crosslinking was dissolved in $0.1 \mathrm{M}$ acetic acid at the concentration of $1 \mathrm{mg} \mathrm{mL}^{-1}$. Thermally denatured collagen was obtained by heating a separated solution prepared from untreated collagen in an oven at $95{ }^{\circ} \mathrm{C}$ for $30 \mathrm{~min}$. Subsequently, CD spectra were recorded on a Jasco Model J-815 CD spectrometer (Jasco, Great Dunmow, UK) at a scan speed of $100 \mathrm{~nm} / \mathrm{min}$ from 190 to $240 \mathrm{~nm}$. The path length of the cuvette was $1 \mathrm{~mm}$. The spectrum of PEO dissolved in $0.1 \mathrm{M}$ acetic acid at the concentration of $0.2 \mathrm{mg} / \mathrm{mL}$ was recorded and used as the baseline. The CD spectra of samples were scanned three times and obtained by averaging. According to the standard method, the fraction of triple helical collagen in the electrospun samples was calculated as follows [31,32]:

$$
f_{T H}=\frac{[\theta]_{E C}-[\theta]_{D C}}{[\theta]_{U C}-[\theta]_{D C}} \times 100
$$

where $f_{T H}(\%)$ is the fraction of triple helical structure in electrospun collagen. Respectively, $[\theta]_{E C}$, $[\theta]_{U C}$ and $[\theta]_{D C}\left(\mathrm{deg} \mathrm{cm} \mathrm{dmol}^{-1}\right)$ are the ellipticity of electrospun collagen, untreated collagen foam and denatured collagen at wavelength $\lambda$.

\subsection{Characterizations of Crosslinking}

The degree of crosslinking is expressed as the percentage of crosslinking present in a sample with respect to the dry, non-crosslinked control sample cut from the same sheet of electrospun material [25]. 
For the sake of investigating the degree of crosslinking, 2,4,6-trinitrobenzenesulfonic acid solution (TNBS) was used $[29,33]$. The rationale for the test is a kind of colorimetric assay. As the degree of crosslinking increases, the number of free aminos in the collagen would decrease followed by a parallel decrease in the number of binding sites which are available for TNBS to interact with. Three samples with an average mass $1.8 \mathrm{mg}$ were punched from each crosslinking treatment and untreated samples. Then, the samples were placed into a solution of $1.0 \mathrm{~mL} 4 \%(w / v)$ sodium bicarbonate and $1.0 \mathrm{~mL}$ freshly prepared $0.5 \%(v / v)$ TNBS in deionized water and heated at $40{ }^{\circ} \mathrm{C}$ for $2 \mathrm{~h}$. Subsequently, $3 \mathrm{~mL}$ of $6 \mathrm{M} \mathrm{HCl}$ was added to each sample and incubated for an additional $1.5 \mathrm{~h}$ at $60^{\circ} \mathrm{C}$. Finally, the solution was diluted with $5.0 \mathrm{~mL}$ of deionized water. Aliquots of equal volume from each sample were read by a Perkin Elmer Lambda $25 \mathrm{UV}$-visible spectrophotometer operating at $345 \mathrm{~nm}$. The degree of crosslinking was calculated as follows:

$$
\text { Cross }-\operatorname{linked}(\%)=\left(1-\frac{A b s_{c}}{\text { mass }_{c}} / \frac{A b s_{n c}}{\text { mass }_{n c}}\right) \times 100
$$

where $c$ is the crosslinked sample, $n c$ is the non-crosslinked sample. Abs is absorbance at $345 \mathrm{~nm}$. The unit of mass is $\mathrm{mg}$.

A scanning electronic microscope (SEM, TM3000, Hitachi Ltd., Tokyo, Japan) and weight loss ratio were used to investigate the water stability of samples under physiological conditions. The samples $\left(2 \times 2 \mathrm{~cm}^{2}\right)$ were immersed in phosphate buffered saline $(\mathrm{pH}=7.4)$ at $37^{\circ} \mathrm{C}$ for up to 7 days with the solution refreshed every day. Then, the samples were freeze dried to constant weight. In order to characterize the stability performance of morphology under physiological conditions, small squares $(0.5 \mathrm{~cm} \times 0.5 \mathrm{~cm})$ were cut from the samples and gold coated by sputtering. The samples were observed by SEM at an accelerated voltage of $15 \mathrm{kV}$ and a working distance of $10 \mathrm{~mm}$. The weight loss ratio was calculated by weighing the samples before and after incubation in PBS.

$$
\text { Weight }-\operatorname{loss}(\%)=\frac{W_{i}-W_{d}}{W_{i}} \times 100
$$

where $W_{i}$ is the initial dry weight of sample before incubation and $W_{d}$ is the dry weight of sample after incubation in PBS for a certain time period. Five samples were used per time point.

In order to reveal the effect of crosslinking and detect the mechanical properties in an environment, which is more closely to the end use, the tensile properties in dry and hydrated states were examined. Tensile properties of the electrospun fibrous membranes were determined with an electronic Strength Tester (XF-1A, Xin Xian Instrument Co., Ltd., Shanghai, China) using a low force load cell of $100 \mathrm{cN}$ capacity at ambient temperature of $25^{\circ} \mathrm{C}$ and humidity of $60 \%$. Strip-shaped specimens $\left(5 \times 50 \mathrm{~mm}^{2}\right)$ were tested three times at a loading speed of $20 \mathrm{~mm} / \mathrm{min}$ and then the thickness was measured with a digital thickness meter having a sensitivity of $1 \mu \mathrm{m}$. For the hydrated state, the crosslinked samples were immersed in PBS for $24 \mathrm{~h}$ at room temperature prior to testing without changing the testing conditions. Finally, the elastic modulus, ultimate tensile stress, and ultimate tensile strain were calculated from the resultant stress-strain curves.

Fourier transform infrared spectroscopy (FTIR) was applied to analyze the surface functional group changes. Spectra of collagen/PEO nanofibers before and after crosslinking were collected by a Nicolet 6700 FT-IR spectrometer (Thermo Fisher Scientific, Waltham, MA, USA). All spectra were recorded in the wavelength range $4000-600 \mathrm{~cm}^{-1}$.

In order to detect the influence of crosslinking on the thermal properties of the electrospun membranes, DSC (DSC4000, PerkinElmer, Shelton, CT, USA) was carried out under a nitrogen atmosphere (flow rate $50 \mathrm{~mL} / \mathrm{min}$ ). The temperature range was from $25^{\circ} \mathrm{C}$ to $220^{\circ} \mathrm{C}$ with a heating rate of $10^{\circ} \mathrm{C} / \mathrm{min}$.

\subsection{Whole Blood Clotting Assay}

Whole blood clotting measurement was carried out to evaluate the hemostasis of electrospun membranes with different degrees of crosslinking. Whole blood was obtained from male New Zealand 
rabbits from the ear vena using a vacuum tube containing sodium citrate at a ratio of 9:1. All the samples were placed into centrifuge tubes and pre-warmed to $37^{\circ} \mathrm{C}$. Afterwards, the citrated blood $(20 \mu \mathrm{L})$ was dipped into the centrifuge tubes followed by $\mathrm{CaCl}_{2}$ solution $(0.2 \mathrm{M}, 10 \mu \mathrm{L})$ to start coagulation. The samples were then incubated with shaking at $37^{\circ} \mathrm{C}$ for $5 \mathrm{~min}$ and $10 \mathrm{~min}$. After incubation, $5 \mathrm{~mL}$ deionized water was carefully added into the tube along inside wall. Red blood cells (RBCs) that were not trapped in the stable clot were hemolyzed by the deionized water. After $5 \mathrm{~min}$, the supernatant was transferred into a new tube and then mixed well at room temperature. The absorbance of samples at $540 \mathrm{~nm}$ was measured by a microplate reader (Tecan, Salzburg, Austria). At the same time, the absorbance of $20 \mu \mathrm{L}$ citrated blood mixed with whole $5 \mathrm{~mL}$ deionized water at $540 \mathrm{~nm}$ was also measured. The blood clotting index (BCI) of samples can be calculated by the following equation [34]:

$$
\mathrm{BCI}(\%)=\frac{I_{t}}{I_{w}} \times 100
$$

where, $I_{t}$ is the absorbance of blood which had contact with the sample at $540 \mathrm{~nm}$ and $I_{w}$ is the absorbance of $20 \mu \mathrm{L}$ whole blood hemolyzed with $5 \mathrm{~mL}$ deionized water at $540 \mathrm{~nm}$.

\subsection{Cell Proliferation Analysis}

Human umbilical vein endothelial cells (HUVEC001) were supplied by Allcells Company (Shanghai, China) and cultured in Dulbecco's modified Eagle's medium (DMEM) with 10\% fetal bovine serum (FBS, Gibco, Shanghai, China) and $1 \%$ penicillin-streptomycin (Gibco) at $37{ }^{\circ} \mathrm{C}$ in a $5 \% \mathrm{CO}_{2}$ incubator. Prior to cell seeding, electrospun membranes (circle with $14 \mathrm{~mm}$ in diameter) were sterilized by immersion in $75 \%$ ethanol for $2 \mathrm{~h}$, followed by washing 3 times with PBS. Then, electrospun membranes with different crosslinking degrees and tissue culture plates (TCP) substrate used as control were placed into the individual wells on a 24-well plate. Three parallel replicates were evaluated for each sample.

Cell proliferation was assessed using the Cell Counting Kit-8 (CCK-8). The cells were seeded into a 24-well plate with sterile samples at a density of $5 \times 10^{4}$ cells/well and cultured for 1 day to 7 days. The medium was refreshed every other day. After 1,3, 5 and 7 days of cell seeding, a $40 \mu \mathrm{L}$ CCK-8 solution was added to each well for $4 \mathrm{~h}$. Then, $100 \mu \mathrm{L}$ of solution was pipetted from each well and quickly transferred into a 96-well plate. The optical density was measured at $450 \mathrm{~nm}$ (OD 450) by a microplate reader (Tecan, Austria).

For all the experiments, the results were expressed as mean \pm standard deviation. For statistical analysis, all data were analyzed by one-way Analysis of Variance (ANOVA) with Tukey's post hoc test for multiple comparison. Significant difference was considered when $p<0.05\left({ }^{*}\right), p<0.01\left(^{* *}\right)$, or $p<0.001{ }^{(* * *)}$.

\section{Results and Discussion}

\subsection{Triple-Helical Configuration Analysis}

In order to evaluate the fraction of the triple helical structure present in electrospun collagen from the 1:1 ratio of the HFIP/HAc mixture solution, circular dichroism measurements were utilized. As shown in Figure 1, the CD spectra of the electrospun collagen, raw and denatured collagen all displayed a sinusoidal pattern. A deep negative peak around $198 \mathrm{~nm}$ and a small positive peak around $220 \mathrm{~nm}$ in the spectrum of untreated collagen represent the well-preserved triple-helical configuration of raw collagen $[31,35]$. Conversely, the thermally denatured collagen showed a weakened negative peak and no positive peak, indicating the absence of the triple-helical structure. In contrast with the spectrum of untreated collagen, electrospun collagen showed a similar spectrum with weakened peaks of negative and positive bands, indicating that the triple helical configuration of electrospun collagen was partly destroyed but still retained. According to previous studies, the solvent system or stirring process would destabilize the triple helical structure of the collagen. In this research, a triple helical fraction around 
$60.5 \%$ was retained by calculation from the positive peak using Equation (1). This indicated that the mixture solvent led to a lower degree of protein denaturation as compared with others $[32,36]$.

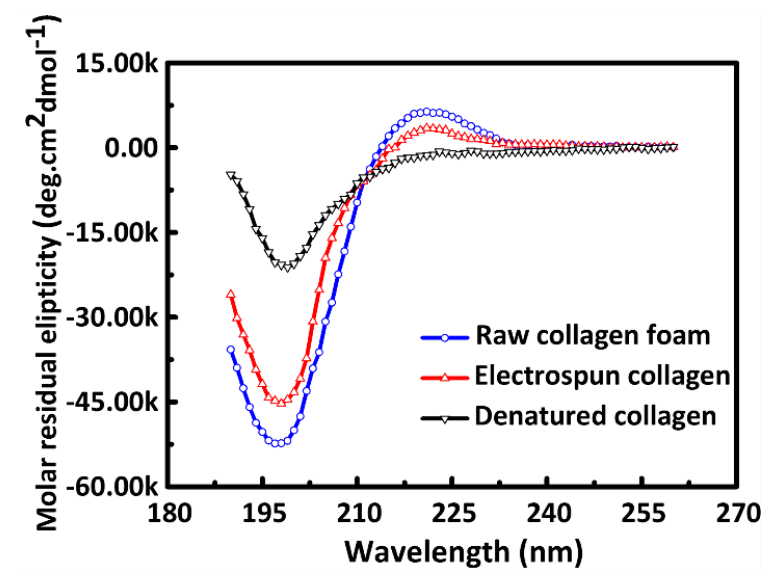

Figure 1. Circular dichroism spectra (baseline subtracted) of raw collagen, electrospun collagen and denatured collagen.

\subsection{Degree of Crosslinking}

According to TNBS assay, percentages of free amino groups in electrospun membranes crosslinked for different time were measured. As illustrated in Figure 2, a sustained increase in the degree of crosslinking was observed with the prolonging of time. To relate in detail, $30.8 \%$ of the available sites were crosslinked in the $6 \mathrm{~h}$ crosslinked sample. For the samples crosslinked for 12, 18 and $24 \mathrm{~h}$, the average degree of crosslinking increased to $48.2 \%, 60.6 \%$ and $62.2 \%$, respectively. However, there was no obvious increase in the degree of crosslinking after crosslinking for $18 \mathrm{~h}$. In fact, there was no statistical differences in the degree of crosslinking between $18 \mathrm{~h}$ and $24 \mathrm{~h}$. It has been reported that the coupling reaction in the initial crosslinking approach is mainly concentrated on the outer surface of collagen fibers due to the slow penetration of crosslinking agents into dense fibers [37]. In our study, for 6 and $12 \mathrm{~h}$ crosslinked samples, the crosslinking reaction mainly occurred on the outer surface of electrospun fibers, followed by a sharp increase in the degree of crosslinking. The number of available sites for crosslinking was gradually decreased on the outer surface, which limits the effect of increasing crosslinking time. When the time exceeded $18 \mathrm{~h}$, there was almost a small amount of available sites for GA on the outer surface, followed by a tiny increase.

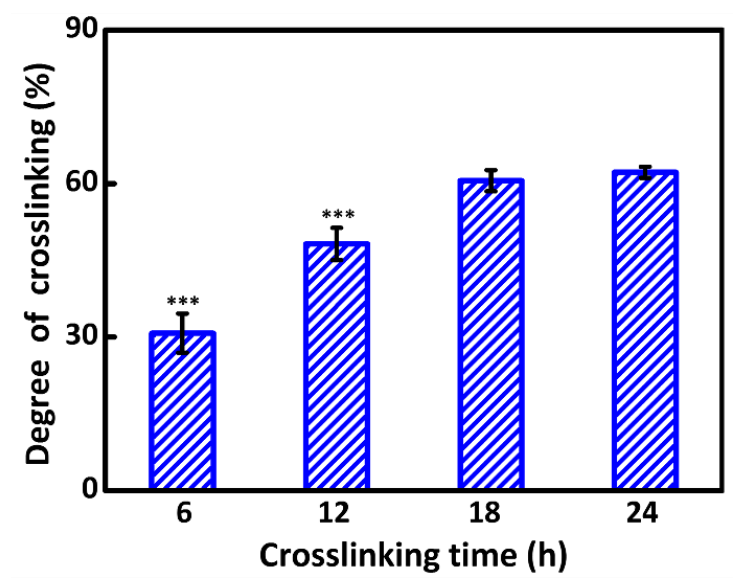

Figure 2. Analysis of degree of crosslinking introduced into collagen nanofibrous membranes as a function of the crosslinking time (Significant differences were marked by ${ }^{* * *}$ for $p<0.001$ compared to the $18 \mathrm{~h}$ and $24 \mathrm{~h}$ crosslinking). 


\subsection{Water Stability of Electrospun Collagen/PEO Membranes}

As shown in Figure S1, uniform fibers with diameter from 350 to $400 \mathrm{~nm}$ were observed in the dry electrospun mat. Due to theirs hydration effect, non-crosslinked collagen nanofibers possess poor water resistance. The nanofibers would be swollen immediately in aqueous solution. Subsequently, the nanofibrous structure would be destroyed in $1 \mathrm{~h}$ (Figure 3a) and then the electrospun membrane would disintegrate into small fragments over time. Hence, the stability of collagen nanofibers in aqueous solution is essential to be improved by crosslinking treatment to enhance their potential applications. In order to detect the difference of electrospun nanofibers in the behaviour of preserving their fibrous morphology and dissolvability in aqueous solution at different degrees of crosslinking, the micrographs and degradation trends of crosslinked samples in the process of being immersed into $\mathrm{PBS}(\mathrm{pH}=7.4)$ at $37^{\circ} \mathrm{C}$ for up to 7 days were achieved by SEM and weight loss ratio, respectively.

(a)

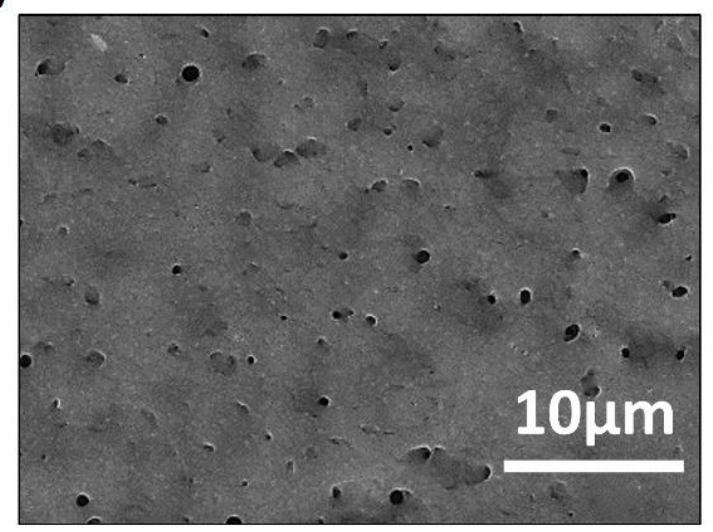

(c)

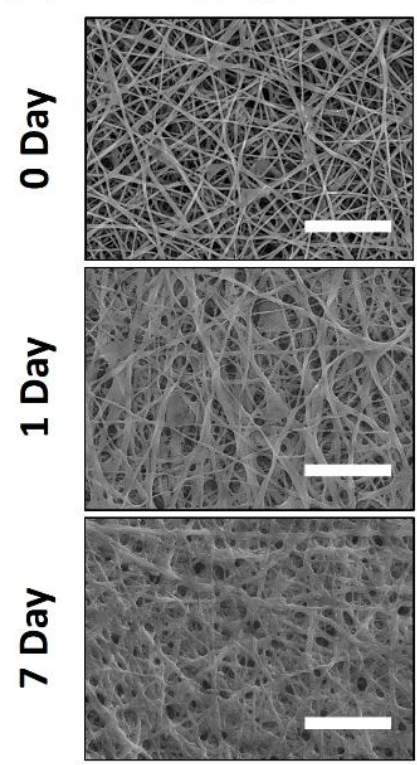

$\mathrm{T}_{\mathrm{C}}=6 \mathrm{~h}$
$48.2 \%$
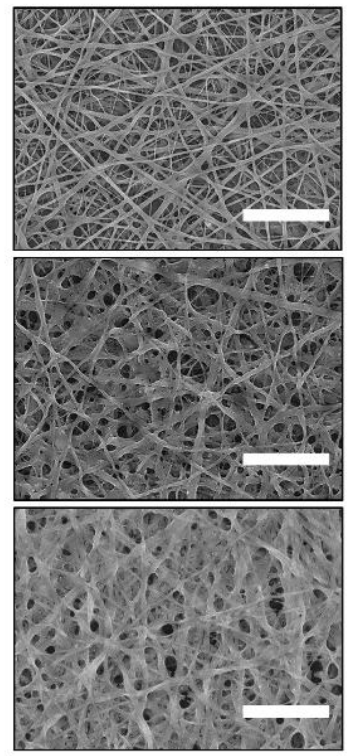

$\mathrm{T}_{\mathrm{C}}=12 \mathrm{~h}$ (b)

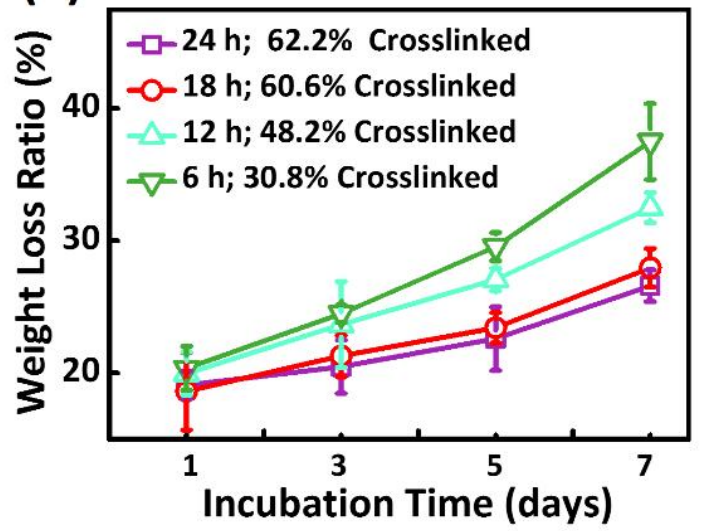

$60.6 \%$

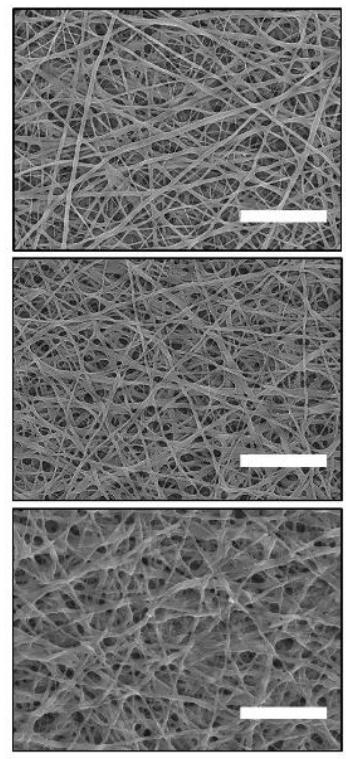

$\mathrm{T}_{\mathrm{C}}=18 \mathrm{~h}$
$62.2 \%$

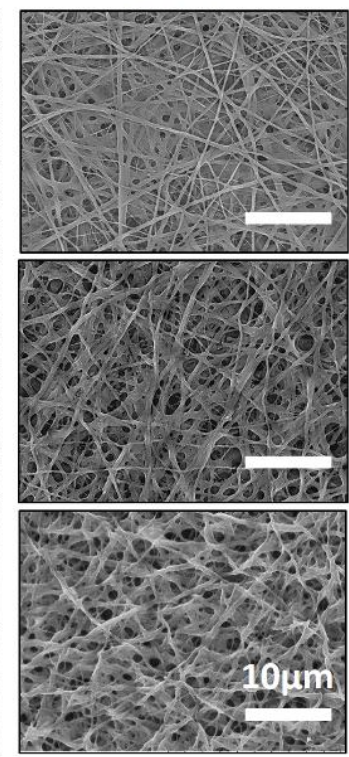

$\mathrm{T}_{\mathrm{C}}=\mathbf{2 4 \mathrm { h }}$

Figure 3. (a) Morphology of non-crosslinked nanofibers after being immersed in Phosphate-buffered saline (PBS) for $1 \mathrm{~h}$; (b) Degradation of crosslinked nanofibrous membranes with varied degrees of crosslinking in PBS at $37^{\circ} \mathrm{C}$ for up to 7 days; (c) Surface SEM micrographs of the membranes possessed varied degrees of crosslinking after incubation in PBS for 0 day, 1 day and 7 days. Scale bar is $10 \mu \mathrm{m}$ for all images. $\mathrm{T}_{\mathrm{C}}$ is the time of crosslinking. 
Degradation trends of different degrees of crosslinked samples are shown in Figure 3b. It suggests that the samples with a sustained increase in the degree of crosslinking possessed weight losses of $20.4 \%, 19.9 \%, 18.6 \%$ and $19.1 \%$ on the first day of incubation, which was higher than the others. This phenomenon may be induced by the removal of water-soluble PEO and the loosely attached fibers $[31,38]$. It has been reported that the possibility of reaction between PEO and glutaraldehyde was extremely low at room temperature [36]. In addition, water-soluble PEO would be extracted after soaking in deionized $\mathrm{H}_{2} \mathrm{O}$ according to other studies [38,39]. After the first incubation day, a substantial increase in the weight loss ratio was observed for all samples for up to 7 days. However, 18 and $24 \mathrm{~h}$ crosslinked samples showed a much slower increase in weight loss ratio compared with 6 and $12 \mathrm{~h}$ crosslinked samples. This prominent diversity was due to the difference in degree of crosslinking. As indicated before, crosslinking took place deeper through the fibers in the 18 and $24 \mathrm{~h}$ crosslinked samples in contrast with 6 and $12 \mathrm{~h}$ crosslinked samples which resulted in more complete crosslinked membranes along with better water stability.

Recently, electrospun nanofibers have shown great potential in wound dressing due to structural mimicry to the native dermal ECM, excellent flexibility, high surface area-to-volume ratio and porosity. Consequently, the nanofibrous structure stability under physiological conditions is very important for wound healing. In order to evaluate the stability of nanofibrous morphology, the crosslinked collagen nanofibrous membranes were immersed into PBS $(\mathrm{pH}=7.4)$ at $37^{\circ} \mathrm{C}$ for up to 7 days. Subsequently, the samples were freeze-dried and their morphologies are shown in Figure 3c. Compared with the non-crosslinked sample (Figure 3a), the nanofibrous morphology of all crosslinked samples were well preserved which confirmed the definite improvement of crosslinking treatment in the water stability of collagen nanofibers. To relate in detail, firstly, all the crosslinked samples without soaking treatment exhibited a slight loss of the nanofibrous morphology due to the coexistence of moisture with GA vapor during crosslinking. Secondly, an obvious loss in the nanofibrous morphology of all crosslinked samples was observed as the immersion time increased. Finally, a better fibrous structure was observed in 18 and $24 \mathrm{~h}$ crosslinked samples for the same immersion time. However, there was no obvious improvement in the fibrous structure between 18 and $24 \mathrm{~h}$ crosslinked samples for the unapparent increase in the degree of crosslinking. In a word, the morphology stability under physiological conditions was consistent with the degree of crosslinking. This phenomenon was in accordance with the trend of the result of the weight loss ratio. The results of the weight loss ratio and SEM micrographs after incubation in PBS for up to 7 days implied that prolonged time $\left(T_{C} \geq 18 \mathrm{~h}\right)$ had little effect on the water stability of electrospun collagen and $60.6 \%$ crosslinked samples showed enough water stability for 1 week.

\subsection{Mechanical Properties Analysis}

Mechanical property is essential for electrospun membranes to provide enough support as a wound dressing [40]. Hence, except for non-crosslinked collagen membrane in the hydrated state, the uniaxial tensile testing for all crosslinked samples was performed in the dry and hydrated state, and representative curves of the stress-strain are presented in Figure S2. The ultimate tensile stress, ultimate tensile strain and elastic modulus in dry state and hydrated are presented in Figure 4. For all crosslinked samples, compared with their dry state, a significant reduction in ultimate tensile stress and elastic modulus coupled with a significant increase in ultimate tensile strain were observed in the hydrated state. It was believed that a pronounced degree of coiling detected in the fiber structure and interfiber motions facilitated by the aqueous testing environment were responsible for these effects [25].

For the testing in the dry state, the average ultimate tensile stress, elastic modulus and ultimate tensile strain of non-crosslinked sample showed a significant difference from all crosslinked samples $(p<0.01)$. A gradually enhanced ultimate tensile stress and elastic modulus and depressed ultimate tensile strain were detected as the degree of crosslinking increased. These are typical effects of increasing crosslinking density in polymeric materials [37]. In addition, the ultimate tensile stress 
of $6 \mathrm{~h}$ crosslinking was significantly different from 18 and $24 \mathrm{~h}$ crosslinking $(p<0.01)$ with no statistical difference observed in elastic modulus and ultimate tensile strain. For the hydrated state, $6 \mathrm{~h}$ crosslinked samples displayed significant differences from 18 and $24 \mathrm{~h}$ crosslinked samples in the average ultimate tensile stress and elastic modulus. In addition, no statistical differences were detected among all crosslinked samples for ultimate tensile strain. Needless to say, no statistical differences for all results in dry and hydrated states were observed between 18 and $24 \mathrm{~h}$ crosslinked membranes. The $60.6 \%$ crosslinked samples exhibited good mechanical properties in dry and hydrated states which could meet the demand of wound dressing.
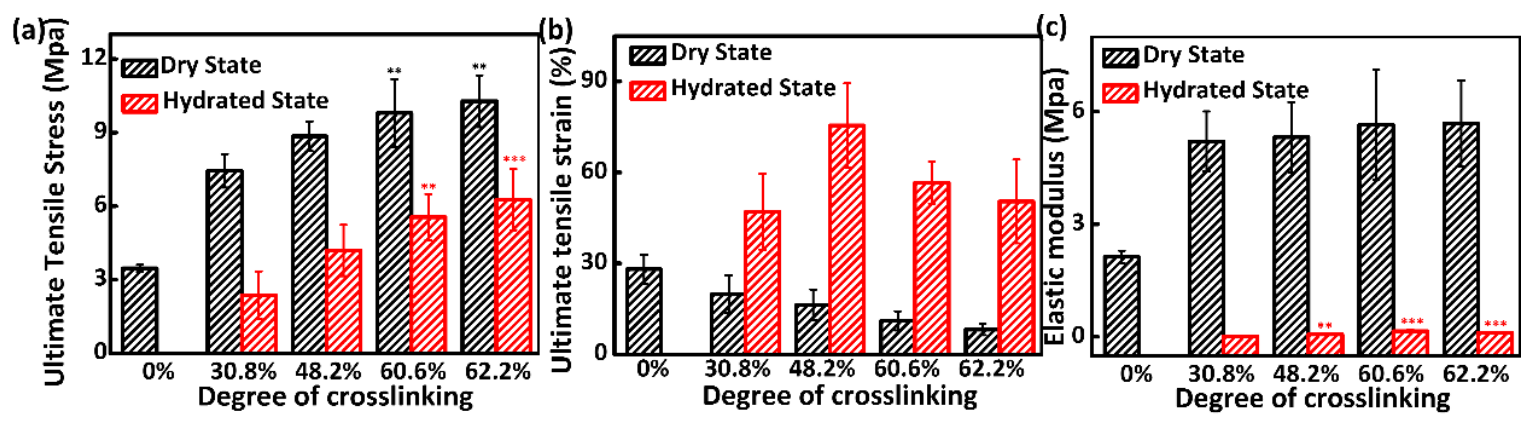

Figure 4. Ultimate tensile stress (a), ultimate tensile strain (b) and elastic modulus (c) of nanofibrous membranes varied as function of degree of crosslinking (Significant differences were marked by *** for $p<0.001{ }^{* *}$ for $p<0.01$ compared to the $30.8 \%$ crosslinked sample).

\subsection{Additional Characterizations}

In order to define the chemical composition changes, Fourier transform infrared spectroscopy results of electrospun collagen/PEO non-crosslinked and $18 \mathrm{~h}$ crosslinked are showed in Figure $5 \mathrm{a}$. In contrast with the non-crosslinked sample, the absorption peak of $\mathrm{N}-\mathrm{H}$ stretching bond around $3300 \mathrm{~cm}^{-1}$ showed a decrease in the $18 \mathrm{~h}$ crosslinked sample for the consumption of amidogens in collagen by the crosslinking treatment. Meanwhile, the characteristic absorption peaks that reflected the conformation of protein polypeptide for collagen were observed at $1650 \mathrm{~cm}^{-1}$ (amide I), $1516 \mathrm{~cm}^{-1}$ (amide II), and $1246 \mathrm{~cm}^{-1}$ (amide III) in both non-crosslinked and crosslinked samples without considerable differences in the location of these characteristic peak. However, the absorption peak of $-\mathrm{C}=\mathrm{N}$ - stretching vibration generated by GA crosslinking was not observed in the range of $1640-1690 \mathrm{~cm}^{-1}$, which may be due to the overlap with strong absorption of the amide I band $\left(1650 \mathrm{~cm}^{-1}\right)$ [24].

DSC was carried out to assess the effect of the crosslinking on the thermal stability of the collagen matrices. During the heating process, the triple-helix structure of collagen will be ruptured. Therefore, the characteristic endothermic peaks have often been termed as denaturation temperature $\left(T_{D}\right)$, which is indeed affected by the degree of crosslinking [41]. As shown in Figure 5b, compared with only one characteristic endothermic peak of the untreated sample, a couple of peaks were found before and after crosslinking of the samples. The DSC of electrospun PEO membrane was carried out to determine whether the weaker endothermic peak near $51^{\circ} \mathrm{C}$ was attributed to the PEO and the left one for collagen. As shown in Figure S3, a single endothermic peak near similar temperature was observed in electrospun $\mathrm{PEO}$ membrane. The $\mathrm{T}_{\mathrm{D}}$ of the non-crosslinked electrospun collagen was about $10.8{ }^{\circ} \mathrm{C}$ lower than that of the untreated collagen foam. This phenomenon was associated with the electrospinning process, which has been explained to result in relatively increased segmental mobility of the fibrous polymers [42]. Compared with the non-crosslinked collagen membrane, $T_{D}$ of the $18 \mathrm{~h}$ crosslinked increased to nearly $9.5^{\circ} \mathrm{C}$. This was probably due to the interchain crosslinking within molecules of crosslinked collagen [43]. DSC results indicated the crosslinking treatment enhanced the thermal stability of the electrospun collagen fibers appreciably. 

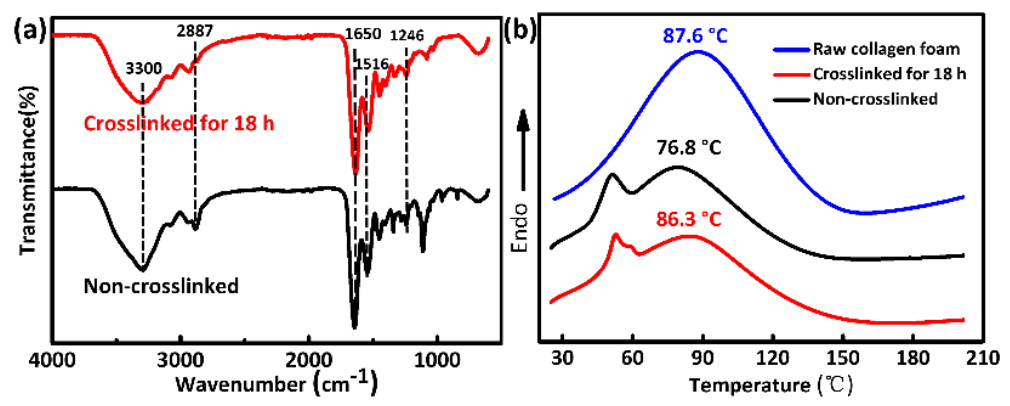

Figure 5. FTIR spectra of collagen/PEO nanofibrous membranes non-crosslinked and crosslinked for $18 \mathrm{~h}$ (a) and DSC thermogram of raw collagen foam, collagen/PEO nanofibrous membranes non-crosslinked and crosslinked for $18 \mathrm{~h} \mathrm{(b)}$.

\subsection{Whole Blood Clotting Assay}

In order to evaluate the blood clotting capacity of the electrospun membranes in vitro, the whole blood clotting experiment for 5 and 10 min was carried out. After incubation with the calcified whole blood and addition of deionized water, the red blood cells (RBCs) not trapped or unstable in clots were ruptured along with the release of hemoglobin. Hence, the concentration of free RBCs can be reflected by the absorbance at $540 \mathrm{~nm}$ [44]. Afterwards, BCI was estimated to characterize the inverse side of the degree of clot formation quantitatively. As illustrated in Figure 6a, with medical gauze as the reference, the BCIs of all electrospun membranes at 5 and 10 min were significantly decreased $(p<0.001)$ which indicated a better blood clotting capability. Meanwhile, the crosslinking treatment of collagen also had an influence on their haemostatic property $(p<0.01)$, whereas no difference was observed between the crosslinked samples when it was crosslinked to $30.8 \%$ or more. Simultaneously, compared with the non-crosslinked collagen, clot formation and the darkness of non-trapped clots dramatically increased in all crosslinked samples (Figure 6b). It is well known that collagen can induce platelet adhesion and aggregation to promote the coagulation process. Therefore, for the electrospun collagen nanofibrous membranes, a stable enough physical support should be provided to promote platelet adhesion and clotting factors binding, culminating in rapid clot formation $[45,46]$. For the non-crosslinked sample, the integrity of its structure would be partially broken followed by unstable support for the clot formation. This is why the BCI value of the non-crosslinked sample exhibited a significant difference from all the crosslinked samples. In addition, a decrease in $\mathrm{BCI}$ values along with the progression of time was observed for all samples except for the non-crosslinked one. This phenomenon was also due to its instability in aqueous solution. Whole blood clotting results indicated the crosslinking treatment enhanced the blood clotting capability of the electrospun collagen fibers appreciably.
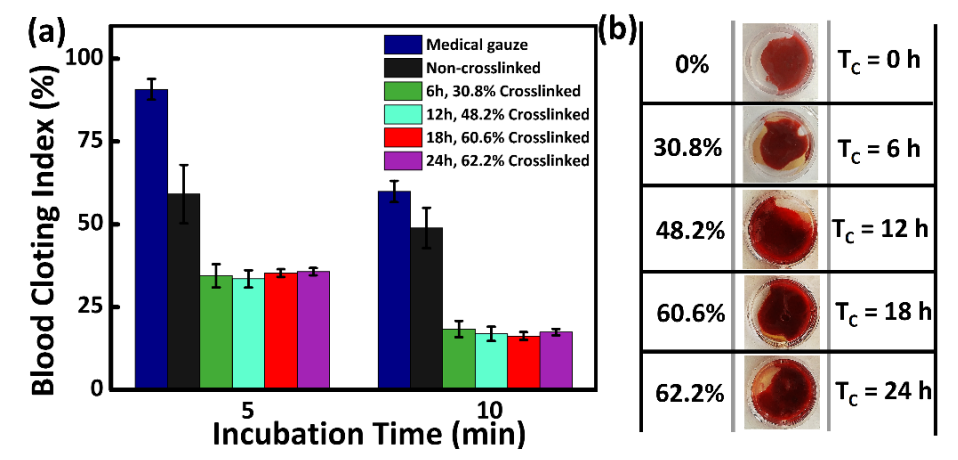

Figure 6. (a) Results of whole blood clotting formation on the medical gauze, non-crosslinked and GA crosslinked electrospun membranes. The clotting formation capacity is expressed as the blood clotting index (BCI), which reflects the free RBCs not trapped in clots. (b) Macroscopic view of whole blood clot formation on various crosslinked electrospun membranes. 


\subsection{Cytocompatibility Analysis}

Cell proliferation of electrospun membranes at different degrees of crosslinking was determined by CCK assay after culturing for 7 days. As shown in Figure 7, for all samples, the cell density increased with prolonged culturing time. No statistical significance on the first day of culturing was observed between the crosslinked samples and the control of TCP substrate, which implied no observable initial inhibition of cell proliferation for all the samples. This was most likely due to the washing step by glycine aqueous solution [43]. After 3 days of culturing, the number of human umbilical vein endothelial cells (HUVECs) on the electrospun membranes after 18 and $24 \mathrm{~h}$ crosslinking was remarkably higher than that after 6 and $12 \mathrm{~h}$ crosslinking. It was hypothesized that the significantly increased cell adhesion was a result of a higher degree of crosslinking. The higher degree of crosslinked membranes showed a lower extent of swelling and a corollary increased modulus. It is reported that increased modulus enhances cell adhesion [47]. In addition, the surface hydrophilicity of material will affect the attachment, proliferation, migration, and viability of many different cells. It was reported that surfaces with moderate hydrophilicity ( $30^{\circ}$ to $70^{\circ}$ related to cells and materials) are most conducive to cell adhesion and spreading [48]. The surface water contact angles were measured and are shown in Figure S4. As crosslinking time increased from $6 \mathrm{~h}$ to $24 \mathrm{~h}$, the average water contact angle increased from $26.6^{\circ}$ to $39.0^{\circ}$ which may support the cell adhesion. Moderate hydrophilicity (Figure S4), increased modulus (as shown in Figure 4c), along with the interstitial spaces (as shown in Figure 3c), would better resemble the extra cellular matrix and provide better physical support and surface, thus upgrading the cell proliferation. It has been reported that the potential cytotoxic of GA may be due to the residues of unreacted GA and leaching out as the materials degrade. In this paper, the thorough glycine quenching followed by crosslinking, which can maximally inactivate the residual aldehyde groups of GA molecules, was proved to be helpful in alleviating the potential cytotoxic of GA crosslinking [18]. The high adhesion under $60.6 \%$ crosslinking indicates that the morphology of collagen fibers is retained and cellular interaction is enhanced.

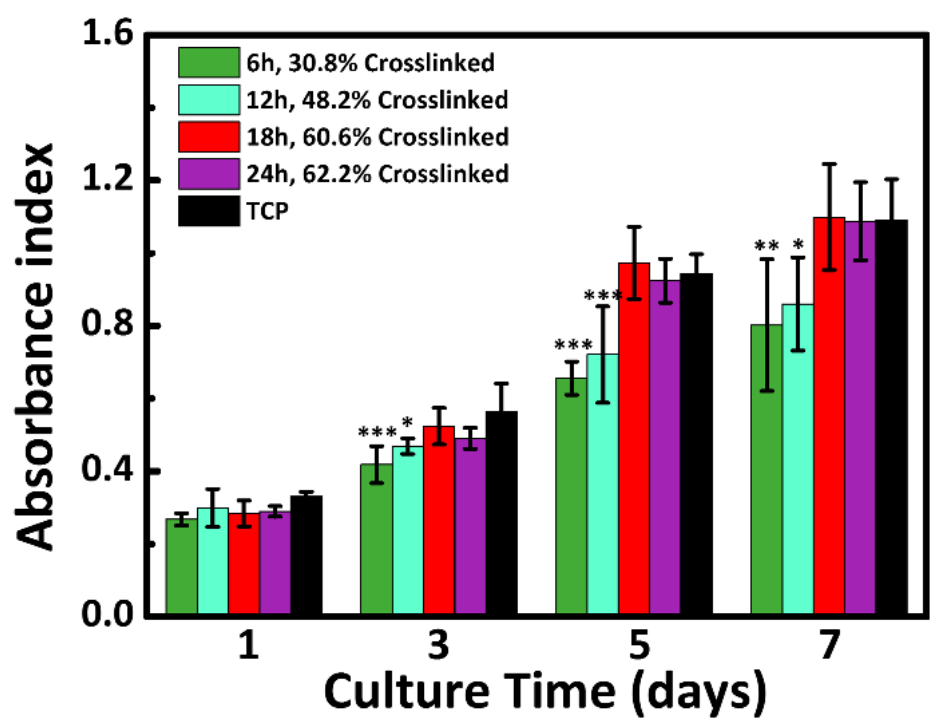

Figure 7. Comparison of cell proliferation by culturing HUVECs on the GA crosslinked electrospun membranes and the controls of Tissue culture plates (TCP) substrate (Significant differences are marked by ${ }^{* * *}$ for $p<0.001$; ${ }^{* *}$ for $p<0.01$; ${ }^{*}$ for $p<0.05$ compared to the TCP substrate).

\section{Conclusions}

In this study, collagen/PEO nanofibrous membranes with varying crosslinking degrees were successfully fabricated by electrospinning and crosslinked by GA vapor for a series of time. Then, correlations between degree of crosslinking and their properties, such as water stability, mechanical 
properties, hemostasis and cytocompatibility were explored. The results showed that water stability and mechanical properties of electrospun membranes were enhanced progressively as the degree of crosslinking increased. For the hemostatic property, it was obvious that the blood clotting capacity of crosslinked samples was enhanced by providing a stable enough physical support for platelet adhesion and clotting factor binding. However, there was no significant difference among the crosslinked $(\geq 30.8 \%)$ samples. In term of cytocompatibility, better-preserved nanofibrous morphology along with higher modulus provided by the higher degree of crosslinking would better resemble the ECM and provide better physical support, thus upgrading the cell proliferation. Hence, with their excellent performance in stability and mechanical properties under physiological condition, the electrospun collagen mats $(60.6 \%$ crosslinked) also possessed better blood clotting formation and cell proliferation. All results suggested that the obtained collagen/PEO nanofibrous membrane has great application potential in wound dressing.

Supplementary Materials: The following are available online at http:/ /www.mdpi.com/2076-3417/8/8/1226/s1, Figure S1: SEM micrographs of non-crosslinked collagen/PEO nanofibers (a) and its diameter distribution (b), Figure S2: Macrographic image of the tensile testing (a), representative curves of the stress-strain of collagen/PEO nanofibrous membranes in the dry state (b) and in the hydrated state (c), Figure S3: DSC thermogram of PEO nanofibrous membranes and non-crosslinked collagen/PEO nanofibrous membranes, Figure S4: Water contact angle of collagen/PEO nanofibrous membranes with varied degrees of crosslinking.

Author Contributions: X.Z. and X.H. conceived and performed the experiments; X.Z., Y.Q. and H.G. analyzed the data; J.G. and L.W. guided the whole experimental process. X.Z. and F.W. wrote the paper.

Funding: This research was funded by the Science \& Technology Project for Major Disease Prevention and Control (No. 2017ZX01001-S22) and Fundamental Research Funds for the Central Universities (No. 2232018G-01).

Conflicts of Interest: The authors declare no conflict of interest.

\section{References}

1. Kanokpanont, S.; Damrongsakkul, S.; Ratanavaraporn, J.; Aramwit, P. An innovative bi-layered wound dressing made of silk and gelatin for accelerated wound healing. Int. J. Pharm. 2012, 436, 141-153. [CrossRef] [PubMed]

2. Casson, J.; O'Kane, S.; Smith, C.A.; Dalby, M.J.; Berry, C.C. Interleukin 6 plays a role in the migration of magnetically levitated mesenchymal stem cells spheroids. Appl. Sci. 2018, 8, 412. [CrossRef]

3. Dhand, C.; Ong, S.T.; Dwivedi, N.; Diaz, S.M.; Venugopal, J.R.; Navaneethan, B.; Fazil, M.H.U.T.; Liu, S.; Seitz, V.; Wintermantel, E. Bio-inspired in situ crosslinking and mineralization of electrospun collagen scaffolds for bone tissue engineering. Biomaterials 2016, 104, 323-338. [CrossRef] [PubMed]

4. Liu, X.; Smith, L.A.; Hu, J.; Ma, P.X. Biomimetic nanofibrous gelatin/apatite composite scaffolds for bone tissue engineering. Biomaterials 2009, 30, 2252-2258. [CrossRef] [PubMed]

5. Rho, K.S.; Jeong, L.; Lee, G.; Seo, B.M.; Park, Y.J.; Hong, S.D.; Roh, S.; Cho, J.J.; Park, W.H.; Min, B.M. Electrospinning of collagen nanofibers: Effects on the behavior of normal human keratinocytes and early-stage wound healing. Biomaterials 2006, 27, 1452-1461. [CrossRef] [PubMed]

6. Torres-Giner, S.; Gimeno-Alcaniz, J.V.; Ocio, M.J.; Lagaron, J.M. Comparative performance of electrospun collagen nanofibers cross-linked by means of different methods. ACS Appl. Mater. Interfaces 2009, 1, $218-223$. [CrossRef] [PubMed]

7. Chen, X.; Xu, Y.; Liang, M.; Ke, Q.; Fang, Y.; Xu, H.; Jin, X.; Huang, C. Honeycomb-like polysulphone / polyurethane nanofiber filter for the removal of organic/inorganic species from air streams. J. Hazard. Mater. 2018, 347, 325-333. [CrossRef] [PubMed]

8. Wang, Y.; Azais, T.; Robin, M.; Vallee, A.; Catania, C.; Legriel, P.; Pehau-Arnaudet, G.; Babonneau, F.; Giraud-Guille, M.M.; Nassif, N. The predominant role of collagen in the nucleation, growth, structure and orientation of bone apatite. Nat. Mater. 2012, 11, 724-733. [CrossRef] [PubMed]

9. Li, H.; Wang, M.; Williams, G.R.; Wu, J.; Sun, X.; Lv, Y.; Zhu, L.-M. Electrospun gelatin nanofibers loaded with vitamins a and e as antibacterial wound dressing materials. RSC Adv. 2016, 6, 50267-50277. [CrossRef]

10. Huang, G.P.; Shanmugasundaram, S.; Masih, P.; Pandya, D.; Amara, S.; Collins, G.; Arinzeh, T.L. An investigation of common crosslinking agents on the stability of electrospun collagen scaffolds. J. Biomed. Mater. Res. Part A 2015, 103, 762-771. [CrossRef] [PubMed] 
11. Zeugolis, D.I.; Khew, S.T.; Yew, E.S.; Ekaputra, A.K.; Tong, Y.W.; Yung, L.Y.; Hutmacher, D.W.; Sheppard, C.; Raghunath, M. Electro-spinning of pure collagen nano-fibres-Just an expensive way to make gelatin? Biomaterials 2008, 29, 2293-2305. [CrossRef] [PubMed]

12. Drexler, J.W.; Powell, H.M. Dehydrothermal crosslinking of electrospun collagen. Tissue Eng. Part C Methods 2011, 17, 9-17. [CrossRef] [PubMed]

13. Raiskup-Wolf, F.; Hoyer, A.; Spoerl, E.; Pillunat, L.E. Collagen crosslinking with riboflavin and ultraviolet-A light in keratoconus: Long-term results. J. Cataract Refract. Surg. 2008, 34, 796-801. [CrossRef] [PubMed]

14. Salvatore, L.; Madaghiele, M.; Parisi, C.; Gatti, F.; Sannino, A. Crosslinking of micropatterned collagen-based nerve guides to modulate the expected half-life. J. Biomed. Mater. Res. Part A 2014, 102, 4406-4414. [CrossRef] [PubMed]

15. Kozlowska, J.; Sionkowska, A. Effects of different crosslinking methods on the properties of collagen-calcium phosphate composite materials. Int. J. Biol. Macromol. 2015, 74, 397-403. [CrossRef] [PubMed]

16. Zhang, X.; Tang, K.; Zheng, X. Electrospinning and crosslinking of col/pva nanofiber-microsphere containing salicylic acid for drug delivery. J. Bionic Eng. 2016, 13, 143-149. [CrossRef]

17. Everaerts, F.; Torrianni, M.; Hendriks, M.; Feijen, J. Biomechanical properties of carbodiimide crosslinked collagen: Influence of the formation of ester crosslinks. J. Biomed. Mater. Res. Part A 2008, 85, 547-555. [CrossRef] [PubMed]

18. Takeda, N.; Tamura, K.; Mineguchi, R.; Ishikawa, Y.; Haraguchi, Y.; Shimizu, T.; Hara, Y. In situ cross-linked electrospun fiber scaffold of collagen for fabricating cell-dense muscle tissue. J. Artif. Organs Off. J. Jpn. Soc. Artif. Organs 2016, 19, 141-148. [CrossRef] [PubMed]

19. Duan, N.; Geng, X.; Ye, L.; Zhang, A.; Feng, Z.; Guo, L.; Gu, Y. A vascular tissue engineering scaffold with core-shell structured nano-fibers formed by coaxial electrospinning and its biocompatibility evaluation. Biomed. Mater. 2016, 11, 035007. [CrossRef] [PubMed]

20. Fessel, G.; Cadby, J.; Wunderli, S.; van Weeren, R.; Snedeker, J.G. Dose- and time-dependent effects of genipin crosslinking on cell viability and tissue mechanics-Toward clinical application for tendon repair. Acta Biomater. 2014, 10, 1897-1906. [CrossRef] [PubMed]

21. Sisson, K.; Zhang, C.; Farachcarson, M.C.; Chase, D.B.; Rabolt, J.F. Evaluation of cross-linking methods for electrospun gelatin on cell growth and viability. Biomacromolecules 2009, 10, 1675-1680. [CrossRef] [PubMed]

22. Powell, H.M.; Boyce, S.T. Edc cross-linking improves skin substitute strength and stability. Biomaterials 2006, 27, 5821-5827. [CrossRef] [PubMed]

23. Fullana, M.J.; Wnek, G.E. Electrospun collagen and its applications in regenerative medicine. Drug Deliv. Transl. Res. 2012, 2, 313-322. [CrossRef] [PubMed]

24. Huang, C.; Chen, R.; Ke, Q.; Morsi, Y.; Zhang, K.; Mo, X. Electrospun collagen-chitosan-Tpu nanofibrous scaffolds for tissue engineered tubular grafts. Colloids Surf. B Biointerfaces 2011, 82, 307-315. [CrossRef] [PubMed]

25. Newton, D.; Mahajan, R.; Ayres, C.; Bowman, J.R.; Bowlin, G.L.; Simpson, D.G. Regulation of material properties in electrospun scaffolds: Role of cross-linking and fiber tertiary structure. Acta Biomater. 2009, 5, 518-529. [CrossRef] [PubMed]

26. Omobono, M.A.; Zhao, X.; Furlong, M.A.; Kwon, C.H.; Gill, T.J.; Randolph, M.A.; Redmond, R.W. Enhancing the stiffness of collagen hydrogels for delivery of encapsulated chondrocytes to articular lesions for cartilage regeneration. J. Biomed. Mater. Res. Part A 2015, 103, 1332-1338. [CrossRef] [PubMed]

27. Sanami, M.; Sweeney, I.; Shtein, Z.; Meirovich, S.; Sorushanova, A.; Mullen, A.M.; Miraftab, M.; Shoseyov, O.; O'Dowd, C.; Pandit, A.; et al. The influence of poly(ethylene glycol) ether tetrasuccinimidyl glutarate on the structural, physical, and biological properties of collagen fibers. J. Biomed. Mater. Res. Part B Appl. Biomater. 2016, 104, 914-922. [CrossRef] [PubMed]

28. Awang, M.A.; Firdaus, M.A.; Busra, M.B.; Chowdhury, S.R.; Fadilah, N.R.; Wan Hamirul, W.K.; Reusmaazran, M.Y.; Aminuddin, M.Y.; Ruszymah, B.H. Cytotoxic evaluation of biomechanically improved crosslinked ovine collagen on human dermal fibroblasts. Bio-Med. Mater. Eng. 2014, 24, 1715-1724.

29. Barnes, C.P.; Pemble, C.W.; Brand, D.D.; Simpson, D.G.; Bowlin, G.L. Cross-linking electrospun type II collagen tissue engineering scaffolds with carbodiimide in ethanol. Tissue Eng. 2007, 13, 1593-1605. [CrossRef] [PubMed] 
30. Marelli, B.; Le Nihouannen, D.; Hacking, S.A.; Tran, S.; Li, J.; Murshed, M.; Doillon, C.J.; Ghezzi, C.E.; Zhang, Y.L.; Nazhat, S.N.; et al. Newly identified interfibrillar collagen crosslinking suppresses cell proliferation and remodelling. Biomaterials 2015, 54, 126-135. [CrossRef] [PubMed]

31. Jiang, Q.; Reddy, N.; Zhang, S.; Roscioli, N.; Yang, Y. Water-stable electrospun collagen fibers from a non-toxic solvent and crosslinking system. J. Biomed. Mater. Res. Part A 2013, 101, 1237-1247. [CrossRef] [PubMed]

32. Liu, T.; Teng, W.K.; Chan, B.P.; Chew, S.Y. Photochemical crosslinked electrospun collagen nanofibers: Synthesis, characterization and neural stem cell interactions. J. Biomed. Mater. Res. Part A 2010, 95, $276-282$. [CrossRef] [PubMed]

33. Nagai, N.; Yunoki, S.; Suzuki, T.; Sakata, M.; Tajima, K.; Munekata, M. Application of cross-linked salmon atelocollagen to the scaffold of human periodontal ligament cells. J. Biosci. Bioeng. 2004, 97, 389-394. [CrossRef]

34. Seon, G.M.; Lee, M.H.; Kwon, B.J.; Kim, M.S.; Koo, M.A.; Kim, D.; Seomun, Y.; Kim, J.T.; Park, J.C. Functional improvement of hemostatic dressing by addition of recombinant batroxobin. Acta Biomater. 2017, 48, $175-185$. [CrossRef] [PubMed]

35. Meng, L.; Arnoult, O.; Smith, M.; Wnek, G.E. Electrospinning of in situ crosslinked collagen nanofibers. J. Mater. Chem. 2012, 22, 19412-19417. [CrossRef]

36. Yang, L.; Fitie, C.F.; van der Werf, K.O.; Bennink, M.L.; Dijkstra, P.J.; Feijen, J. Mechanical properties of single electrospun collagen type i fibers. Biomaterials 2008, 29, 955-962. [CrossRef] [PubMed]

37. Kishan, A.P.; Nezarati, R.M.; Radzicki, C.M.; Renfro, A.L.; Robinson, J.L.; Whitely, M.E.; Cosgriff-Hernandez, E.M. In situ crosslinking of electrospun gelatin for improved fiber morphology retention and tunable degradation. J. Mater. Chem. B 2015, 3, 7930-7938. [CrossRef]

38. Zhao, X.; Chen, S.; Lin, Z.; Du, C. Reactive electrospinning of composite nanofibers of carboxymethyl chitosan cross-linked by alginate dialdehyde with the aid of polyethylene oxide. Carbohydr. Polym. 2016, 148, 98-106. [CrossRef] [PubMed]

39. Jeong, S.I.; Krebs, M.D.; Bonino, C.A.; Khan, S.A.; Alsberg, E. Electrospun alginate nanofibers with controlled cell adhesion for tissue engineering. Macromol. Biosci. 2010, 10, 934-943. [CrossRef] [PubMed]

40. Wang, X.; Cheng, F.; Gao, J.; Wang, L. Antibacterial wound dressing from chitosan/polyethylene oxide nanofibers mats embedded with silver nanoparticles. J. Biomater. Appl. 2015, 29, 1086-1095. [CrossRef] [PubMed]

41. Bedran-Russo, A.K.; Castellan, C.S.; Shinohara, M.S.; Hassan, L.; Antunes, A. Characterization of biomodified dentin matrices for potential preventive and reparative therapies. Acta Biomater. 2011, 7, 1735-1741. [CrossRef] [PubMed]

42. Zhang, Y.Z.; Venugopal, J.; Huang, Z.M.; Lim, C.T.; Ramakrishna, S. Crosslinking of the electrospun gelatin nanofibers. Polymer 2006, 47, 2911-2917. [CrossRef]

43. Zhong, S.P.; Teo, W.E.; Zhu, X.; Beuerman, R.; Ramakrishna, S.; Yung, L.Y.L. Development of a novel collagen-GAG nanofibrous scaffold via electrospinning. Mater. Sci. Eng. C 2007, 27, 262-266. [CrossRef]

44. Cheng, X.; Shao, Z.; Li, C.; Yu, L.; Raja, M.A.; Liu, C. Isolation, characterization and evaluation of collagen from jellyfish rhopilema esculentum kishinouye for use in hemostatic applications. PLoS ONE 2017, 12, e0169731. [CrossRef] [PubMed]

45. Achneck, H.E.; Sileshi, B.; Jamiolkowski, R.M.; Albala, D.M.; Shapiro, M.L.; Lawson, J.H. A comprehensive review of topical hemostatic agents: Efficacy and recommendations for use. Ann. Surg. 2010, 251, 217-228. [CrossRef] [PubMed]

46. Spotnitz, W.D.; Burks, S. Hemostats, sealants, and adhesives: Components of the surgical toolbox. Transfusion 2008, 48, 1502-1516. [CrossRef] [PubMed]

47. Grover, C.N.; Gwynne, J.H.; Pugh, N.; Hamaia, S.; Farndale, R.W.; Best, S.M.; Cameron, R.E. Crosslinking and composition influence the surface properties, mechanical stiffness and cell reactivity of collagen-based films. Acta Biomater. 2012, 8, 3080-3090. [CrossRef] [PubMed]

48. Kim, S.H.; Ha, H.J.; Ko, Y.K.; Yoon, S.J.; Rhee, J.M.; Kim, M.S.; Lee, H.B.; Khang, G. Correlation of proliferation, morphology and biological responses of fibroblasts on ldpe with different surface wettability. J. Biomater. Sci. Polym. Ed. 2007, 18, 609-622. [CrossRef] [PubMed]

(C) 2018 by the authors. Licensee MDPI, Basel, Switzerland. This article is an open access article distributed under the terms and conditions of the Creative Commons Attribution (CC BY) license (http:/ / creativecommons.org/licenses/by/4.0/). 